\title{
EDITORIAL
}

\section{Toward a More Cogent Approach to the Challenges of Multimorbidity}

\author{
Richard A. Goodman, MD, MPH $H^{1,2,3}$ \\ Anand K. Parekh, MD, MPH \\ Howard K. Koh, MD, MPH \\ ${ }^{1}$ National Center for Chronic Disease Prevention and Health Promotion, Centers for Disease Control and Prevention, Atlanta, Georgia \\ ${ }^{2}$ Division of Geriatric Medicine and Gerontology, Emory University School of Medicine, Atlanta, Georgia \\ ${ }^{3}$ Office of the Assistant Secretary for Health, US Department of Health and Human Services, Washington, DC
}

Ann Fam Med 2012;10:100-101. doi:10.1370/afm.1391.

$\mathrm{T}$ This issue of the Annals, as well as the previous one, confronts the enormous public health challenges of multimorbidity. More than 1 in 4 Americans has multiple ( 2 or more) chronic conditions, including physical and behavioral health problems, accounting for an estimated two-thirds of total US health care spending. ${ }^{1}$ An individual's risks for a variety of adverse health outcomes (eg, poor functional status, unnecessary hospitalizations, and adverse drug events) rise as the number of multiple chronic conditions increases. ${ }^{2}$

The Centers for Medicare and Medicaid Services (CMS) has just released even more detailed information with respect to its Medicare fee-for-service populations, ${ }^{3}$ exposing the exceptional complexity and sheer burden that multiple chronic conditions pose for patients, health facilities, payers, and clinicians. In its recently released chart book Chronic Conditions Among Medicare Beneficiaries, ${ }^{3}$ CMS describes detailed demographics and prevalence measures of multiple medical conditions in this population and the dramatic impact on service utilization and spending. Examples of key findings are that two-thirds (20.7 million beneficiaries) had at least 2 or more chronic conditions; about $50 \%$

Conflicts of interest: authors report none.

\section{CORRESPONDING AUTHOR}

Richard A. Goodman, MD

Centers for Disease Control and Prevention

Mailstop K45

4770 Buford Highway NE

Atlanta, GA 30341

rag4@cdc.gov of beneficiaries with stroke or heart failure had 5 or more additional chronic conditions; beneficiaries with 6 or more chronic conditions accounted for about one-half of Medicare spending on hospitalizations; more than one-quarter of beneficiaries with 6 or more chronic conditions had a hospital readmission within 30 days $_{;}$and the $12 \%$ of beneficiaries with 6 or more chronic conditions accounted for $43 \%$ of Medicare spending. For health systems that have traditionally focused on research and treatment of single conditions, these tremendous challenges have forced many to escalate efforts to identify and implement solutions.

How do we as a society bring a greater sense of order to this vexing challenge? As part of the response, the US Department of Health and Human Services (HHS), in conjunction with partner organizations and other stakeholders, used a deliberative process to develop Multiple Chronic Conditions-A Strategic Framework: Optimum Health and Quality of Life for Individuals with Multiple Chronic Conditions. ${ }^{2}$ The framework serves as a national-level road map to assist HHS programs and public and private stakeholders in ensuring a more coordinated and comprehensive approach to improving the health status of individuals with multiple chronic conditions. ${ }^{2,4}$ Released to stakeholders and the public in late 2010, the framework is organized into 4 major goal areas with subsets of objectives and action strategies for use by clinical practitioners, policy makers, researchers, and others. The framework's goals encompass the interdependent domains of (1) strengthening the health care and public health systems ${ }_{i}(2)$ empowering the individual to use self-care management ${ }_{i}$ (3) equipping health care clinicians with tools, information, and other interventions; and (4) supporting tar- 
geted research about individuals with multiple chronic conditions and effective interventions.

The 3 articles on multimorbidity included in this issue of the Annals, ${ }^{5-7}$ which focus on measurement, represent progress in better understanding the epidemiology of multiple chronic conditions, a key aspect of the HHS strategic framework's fourth goal. The articles further illustrate that there are multiple operational definitions of multimorbidity, each with their respective strengths and weaknesses. Though each may be appropriate according to the outcome of interest, there also may be utility for some degree of standardization in characterizing this heterogeneous population. The definition for multiple chronic conditions used in the HHS strategic framework utilized an approach of simple counts of conditions (ie, 2 or more). The article by Huntley et al, consistent with this approach, finds that simple counts of diseases perform almost as well as complex measures in predicting most outcomes. ${ }^{5}$ Ultimately, however, from a policy perspective, what generally holds true irrespective of the selected measure is that as the magnitude of multimorbidity increases, patient outcomes decline and costs rise. Thus, targeting care management efforts on multimorbid populations should, in principle, accelerate the country's progress toward the goals of delivery system reform.

We invite readers to further their familiarity with the complex issues posed by multiple chronic conditions by reviewing the HHS strategic framework and related activities (http://www.hhs.gov/ash/initiatives/ mcc). ${ }^{8}$ A current HHS collaborative initiative-led by CMS, the Centers for Disease Control and Prevention, and the Agency for Healthcare Research \& Quality-is not only examining options for a conceptual framework to improve definition and measurement of priority chronic conditions, but also is conducting coordinated analyses of multiple data sets to improve descriptive epidemiological characterization of mul- tiple chronic conditions. Increasing life expectancy and the aging of the population will only intensify the challenge for the future. The articles in this issue begin to address an enormous health system challenge that demands our urgent attention.

To read or post commentaries in response to this article, see it online at http://www.annfammed.org/content/10/2/100.

Key words: chronic disease; comorbidity; multiple chronic conditions

Submitted February 3, 2012; accepted February 8, 2012.

\section{References}

1. Anderson G. Chronic Care: Making the Case for Ongoing Care. Princeton, NJ: Robert Woods Johnson Foundation, 2010. http:// www.rwjf.org/files/research/50968chronic.care.chartbook.pdf. Accessed Jan 30, 2012.

2. US Department of Health and Human Services. Multiple Chronic Conditions-A Strategic Framework: Optimum Health and Quality of Life for Individuals with Multiple Chronic Conditions. Washington, DC: US Dept Health \& Human Services; 2010. http://www.hhs.gov/ash/ initiatives/mcc/mcc_framework.pdf. Accessed February 16, 2012.

3. Centers for Medicare \& Medicaid Services. Chronic Conditions Among Medicare Beneficiaries, Chart Book. Baltimore, MD. 2011. http://www.cms.gov/TheChartSeries/Downloads/ChartbookFinal.pdf. Accessed Jan 30, 2012.

4. Parekh AK, Goodman RA, Gordon C, Koh HK. Managing multiple chronic conditions: a strategic framework for improving health outcomes and quality of life. Pub Health Rep. 2011;126(4):460-471.

5. Huntley AL, Johnson R, Purdy S, Valderas JM, Salisbury C. Measures of multimorbidity and morbidity burden for use in primary care and community settings: a systematic review and guide. Ann Fam Med. 2012;10(2)134-141.

6. Fortin M, Stewart M, Poitras M, Almirall J, Maddocks H. A systematic review of prevalence studies on multimorbidity: toward a more uniform methodology. Ann Fam Med. 2012;10(2)142-151.

7. Bayliss EA, Ellis JL, Shoup JA, Zeng C, McQuillan DB, Steiner JF. Association of patient-centered outcomes with patient-reported and ICD-9-based morbidity measures. Ann Fam Med. 2012;10(2)126-133.

8. US Department of Health and Human Services. HHS Initiative on Multiple Chronic Conditions. http://www.hhs.gov/ash/initiatives/ mccl. Accessed Jan 30, 2012. 